\title{
Involving relevant stakeholders into the decision process about software components
}

\author{
Krzysztof Wnuk \\ Department of Software Engineering, \\ Blekinge Institute of Technology \\ Karlskrona, Sweden \\ Email: Krzysztof.Wnuk@bth.se
}

\begin{abstract}
This papers surveys current stakeholder identification methods and techniques from the Requirements Engineering (RE) discipline. Upon critical analysis of available models and techniques, we identify the techniques that should be prioritized when identifying stakeholders that should be involved in the decision making processes about software components or assets. Next, we analyzed industrial decision scenarios and match the most prominent issues with stakeholder identification against the perceived benefits that the identified techniques offer. We conclude this paper with a research agenda in stakeholder identification for decision making about software components.
\end{abstract}

\section{INTRODUCTION}

Successful software-intensive product development needs to be based, among others, on the two interconnected activities: accurate identification of correct requirements and accurate identification of stakeholders that believe these requirements are important for them [1]. Delivering requirements that have no associated stakeholders creates a substantial risk of product failures and is a frequent issue among technology-push companies [2]. Thus, software product managers and other associated decision makers need efficient methods for identification and analysis of relevant stakeholders while this area has generally been overlooked by the researchers [3], [4].

This paper surveys the current literature about stakeholder identification and the literature in Requirements Engineering and combines it with the results of two industrial investigations about decision making for software components. We discuss the techniques that should be prioritized when identifying stakeholders in the decision making processes about software components. Upon critical analysis of the decision scenarios, we match the most prominent issues in stakeholder identification against the perceived benefits that the identified techniques offer. We conclude this paper with a list of potential research avenues in stakeholder identification for decision making about architecturally significant components.

\section{Stakeholder IDENTIFICATION IN SOFTWARE AND REQUIREMENTS ENGINEERING}

Software Engineering articles acknowledge the importance of stakeholder identification. SWEBOK [5], SEI [6], ISO [7] and RUP [8] all highlight that relevant stakeholders should be identified early in the product lifecycle process. At the same time, these reports consider stakeholder identification as "obvious" and therefore underestimate the challenges associated with it. The ISO/IEC/IEEE 42010 standard [9] emphasizes various stakeholders, and their viewpoints, that frame one or more concerns held by stakeholders about the system of interest. The standard considers all stakeholders equally important, which resembles the issue highlighted by Boehm regarding value-neutral software engineering [10]. Framing stakeholder concerns and architectural views have shown promising results for resulting conflicts between stakeholders and improving architectural documentation [11].

Several authors provide various descriptions or categories of stakeholders, e.g. clients/sponsors, users, developers, quality personnel, security personnel and the requirements analyst [6], customers, quality personnel, software developers [7], business managers, brand managers, marketing staff, external and internal customers, consultants, product engineers, software engineers, support and maintenance engineers [12] end users, developers or business managers [13] or users, sponsors, test staff, business analysts, technology experts, system designers, marketing experts, legal experts, IT specialists, usability experts, representatives of external associations [14] just to name a few. From these listings we see a clear division between the customer-associated roles (the customer or end user and associated roles) and the product development roles (developers, architects and managers). What becomes apparent, is that decision makers are not explicitly placed among the stakeholders by these works (assuming that appropriate decisions are made in timely manner by appropriate stakeholders or that managers always make decisions).

$\mathrm{Gu}$ et al. presented a taxonomy of stakeholder types and roles for SOA projects with the following five roles: service providers, application builders, service composers and application clients then maps these roles onto the various lifecycle phases [15]. Decision making is not highlighted among the lifecycle phases, suggesting that it may be done during early requirements engineering. The paper also admits that end-users cannot be classified using the taxonomy. Another interesting finding is that no service broker role was identified, suggesting limited support between service providers and service consumers.

A relevant perspective for decisions about software assets or components is to identify stakeholders focusing on what they 
want (their goals and potential risks) [16] or the differences between their wishes and real needs [14]. Moreover, focusing on interactions between stakeholders [17]-[19] appears to be promising for improved decision making. However, these two directions are substantially more challenging to apply in industrial contexts as they go beyond simple classifications or counting.

Stakeholder assessment or categorization appears to be dominant for decision making scenarios as several authors propose various categorizations of stakeholders. Categorization can be based on multiple criteria, e.g. power, legitimacy and urgency [20] or motivation and ability to influence outcomes [21]. McManus categorize stakeholders into primary, secondary, external and extended [21]. Tovar and Pacheco proposed three criteria for analyzing stakeholder identification methods: 1) role establishment and contribution in the requirements specification state, 2) skills analysis (knowledge and experience that is required in a given role), 3) the maturity of the method [4]. Our previous work on decision making taxonomy classifies stakeholders (Roles) into: types (asset supplier, asset user, system end-user), function (initiator, supporter, influencer and decider) and levels (strategic, tactical and operational) [22].

\section{LOOKING AT STAKEHOLDER IDENTIFICATION Through THE LENS OF INDUSTRIAL DeCision CASES}

A recent case survey about choosing component origins for software intensive systems summarizes the roles and stakeholders involved in decision making categorizing them into: 1) decision initiators, 2) decision "preparators" and 3) decision makers [23]. Decision initiators were mostly managers in the surveyed cases with multiple roles initiating the decisions in three analyzed cases and executives in six cases. Decision "preparators" were mostly software management and software design/construction roles supporting the decision discussion with expert input. The cases do not explicitly mention RE related roles as "preparators" while this would be a natural ways of including RE knowledge and techniques into the decision making process.

Surprisingly, customers were involved only in three cases, sub-contractors in three cases and testers only in two cases. Decision makers were primarily managers with consensus achieved between managers and developers or architects in two cases. The survey also highlighted that one role was involved in both initiation and decision making, while on average three roles supported decision preparation.

An interesting finding surfaced when performing retrospective analysis of the cases: the decisions were perceived positive in only seven cases. The main frustration was the extensive effort investigated in preparing for the decision that could be considered a waste [23]. As decision makers usually do experience based judgments, this points to two improvement areas: supporting decision "preparators" with additional analysis methods and developing a decision support system that can, to some degree, support or replace expert judgment and decrease the subjectivity of the decisions [24]. The first improvement area can be addressed by employing requirements engineering and analysis techniques as it is similar to one of the classical failures of requirements engineering, developing the wrong system that the customers are not happy with.

Upon critical reflection of these results we can draw a parallel between requirements engineering and decision making processes, also emphasized by Aurum and Wohlin [24]. The initiators could be considered similar to sources of requirements (end customers, internal customers or other roles fromwhich the requirements originate), the "preparators" correspond to the requirements engineers or analysts who take the requirements from the sources, analyze them, specify and prepare for decision making and, finally, the decision makers are similar for both decision making and requirements engineering phases. The main findings from the cases is that decision "preparators" are software management or construction (developers) rather than requirements analysts or engineers (who usually have good experience in identifying relevant stakeholders).

Another recent study categorizes 29 industrial cases [25] with the help of the GRADE taxonomy of decision making [22]. The study classifies stakeholders involved in these decisions into the Roles element of the taxonomy. Roles have different types (asset supplier, asset user, system enduser), function (initiator, supporter, influencer and decider) and levels (strategic, tactical and operational). The analysis brings interesting findings. Only in $15 \%$ of cases the enduser role was identified and only in $60 \%$ of the cases the user role was identified. Similarly, only in $60 \%$ of the cases the supporter role was identified. These findings suggest that decision makers lack operational support for efficient role identification that can help with collecting and analysing the required information as well as influencing other roles in a timely manner.

The experts involved in coding the decision cases with the help of GRADE pointed out several challenges with the Roles element. For example, it was challenging to accurately tag the level of decision (strategic, tactical or operational) and the decision level was often decided based on the roles involved, e.g. if executives were involved this indicates a strategic decision. Moreover, in all cases multiple roles were involved and the experts had difficulties in understanding how these roles interact with each other, strengthening the need for improved iterative stakeholder analysis.

\section{COMPARATIVE ANALYSIS OF STAKEHOLDER IDENTIFICATION METHODS}

Table I lists the prominent challenges in decision making (both strategic and operational) against the methods that have the potential to mitigate these challenges. The challenges greatly overlap with Requirements Engineering challenges, in a broad sense, and both RE and decision making suffer from inefficient stakeholder/requirements identification. 
TABLE I

THE ANALYSIS OF CHALLENGES IN INVOLVING RELEVANT ROLES IN DECISION MAKING AGAINST THE STAKEHOLDER IDENTIFICATION METHODS THAT HAVE THE POTENTIAL TO ADDRESS THESE CHALLENGES.

\begin{tabular}{|c|c|}
\hline CHALLENGE & POTENTIAL METHODS AND REMEDIES \\
\hline $\begin{array}{l}\text { End-user involvement end-users were identified only in } 15 \% \\
\text { of the cases and users in } 60 \% \text { of the cases. Two studies } \\
\text { introduce also customers as an important stakeholder to be } \\
\text { identified [6], [7]. Moreover, mostly managers were initiators } \\
\text { and makers for the decisions. This created a question if the } \\
\text { action was triggered by the managers after analyzing end- } \\
\text { user or user feedback or only assuming that these roles will } \\
\text { appreciate and accept the proposed change? }\end{array}$ & $\begin{array}{l}\text { Established methods for involving stakeholders [14], [16] have the potential to bring } \\
\text { remedies here. Moreover, data-driven and experiment-driven approaches should also } \\
\text { be utilized for stakeholders identification in decision making as they are currently } \\
\text { explored for requirements identification [26]. We should also look at what crowd- } \\
\text { based RE is offering and whether we could apply some of the findings to stakeholder } \\
\text { identification and analysis [27]. These identified in a bottom-up fashion voices may } \\
\text { bring important perspectives and properties that should be weighted when making } \\
\text { the decisions. These perspectives are currently mostly utilized for operational or more } \\
\text { technical decisions (e.g. asking end users about a new functionality) and should also } \\
\text { be taken into consideration when making strategic decisions. Also, the influence of } \\
\text { end-users to confirm or reverse decisions made should be further explored. }\end{array}$ \\
\hline $\begin{array}{l}\text { Separating stakeholders' wishes and real needs is es- } \\
\text { pecially relevant when deciding which properties [28] are } \\
\text { important for a given decision and what trade-offs need to be } \\
\text { made between often conflicting non-functional aspects [29]. }\end{array}$ & $\begin{array}{l}\text { The VOLERE template for requirements process helps to discover the difference } \\
\text { between a stakeholder's wish and a real need [14] and the Kano model helps to } \\
\text { distinguish between the must-be quality, attractive, indifferent and reverse quality [30]. } \\
\text { The requirements triage process constrains what can be delivered by time given and } \\
\text { resources available and therefore helps to sort out wishes and keep the real needs [31] } \\
\text { while trade-offs between non-functional properties help to understand which of them } \\
\text { are dominant for which decision [29]. }\end{array}$ \\
\hline $\begin{array}{l}\text { Most research focuses on categorizing rather than explor- } \\
\text { ing relationships, dynamic behavior and interactions and } \\
\text { there exist several categorization shema [5]-[7], [12], [13], } \\
{[16] \text { and only some authors emphasize interactions [17], [19]. }}\end{array}$ & $\begin{array}{l}\text { Established work on stakeholder identification suggests to explore the network of } \\
\text { stakeholders around some "baseline" stakeholders (users, developers, legislators, and } \\
\text { decision-makers) [17]. Property ontologies relevant for given decision [28] and ontolo- } \\
\text { gies of stakeholders or customers could be helpful here [32]. Interdependency analysis } \\
\text { can also be helpful in studying dependencies between stakeholders involved in decision } \\
\text { making [33] as well as social-network analysis of stakeholders [2]. }\end{array}$ \\
\hline $\begin{array}{l}\text { The decision is perceived positive only in a fraction of } \\
\text { cases and this could be related to the fact that most decision } \\
\text { makers apply expert opinion to analyze possible alterna- } \\
\text { tives [23] and limited support that the "preparators" receive } \\
\text { to decrease the subjectivity of the decisions [24]. These are } \\
\text { similar to one of the fundamental challenges in requirements } \\
\text { engineering, the lack of sufficient investment in RE leads to } \\
\text { developing unsuccessful products [14], [16] as subjective or } \\
\text { political decisions replace thorough requirements analysis. }\end{array}$ & $\begin{array}{l}\text { A variety of requirements engineering techniques could be applied here [14], [16], } \\
\text { starting from stakeholder identification and analysis and concluding with requirements } \\
\text { validation techniques. Early user involvement appears to be important for both re- } \\
\text { quirements engineering and decision making [34] and should be combined with novel } \\
\text { requirements validation methods that not only verify and validate requirements [14], } \\
\text { [16] but also the stakeholders that these requirements are originating from. }\end{array}$ \\
\hline
\end{tabular}

\section{Conclusions and Potential Research Avenues}

Involving relevant stakeholders in the decision process about architecturally significant assets is important for making objective and balanced decisions that do not need to be reversed. This is particularly important for decisions about components that will serve their purpose for years and can generate or save substantial maintenance costs.

This paper confirms that RE and decision making are closely related with each other, this relationship was already emphasized in 2003 [24]. At the same time, the paper sheds light on the similarity of the stakeholder identification related challenges and opportunities in both areas. We discovered that managers both prepare and make decision and that they lack clear support from involved requirements engineers or analysts.

Based on the analysis provided in this paper, we emphasize the need for looking deeper into stakeholder identification as an integral part of decision making. Moreover, the risk for project failure is amplified if wrong requirements are developed from wrongly selected stakeholders and prioritized with wrongly selected roles involved in the requirements selection process. This triple negative effect can be minimized if more effort is dedicated to improved stakeholder identification for decision making.
We conclude this paper with the list of potential research avenues:

- Research Avenue 1: Improved methods for identifying end-users or users that should participate in decision making. This involves identifying users who represent correct and consistent picture of what a system should do but can also support the decision making process with relevant decision criteria and property estimates. Eliciting these should help in separating real needs and necessary property levels from wishes and help increase objectivity in decision making.

- Research Avenue 2: Exploring the relationships between the stakeholder roles or categories and how these impact decision making. Current research focuses primary on dependencies between requirements [33] or categorizing stakeholders [6], [7] or roles involved in decision making [25]. Looking deeper at the interactions between these stakeholders can uncover important relationships that may lead to improved decision making, for example further exploring conflict resolution methods in software architecture and architectural viewpoints.

- Research Avenue 3: Minimizing disappointment with decisions. Since only a fraction of the surveyed industrial decisions were considered positive, see Section III, there is a need to investigate and to propose better decision sup- 
port that minimizes this negative phenomenon. Current requirements engineering techniques and their suitability in overcoming the challenge of designing the wrong system for the wrong customers should be put against the challenge of identifying the right stakeholders for decision making. Architectural views and their potential to resolve conflicts should also be explored here [11].

- Research Avenue 4: Explore how architectural viewpoints and separation of concerns can be used for supporting decision making and resolving conflicts between stakeholders in decision making [11]. The ISO/IEC42010 standard recommends architecture descriptions to frame one or more stakeholder concerns about the system of interest.

We do not claim that the above listed research agenda is complete and welcome additional aspects; these aspects are distilled from our previous work on industrial decisions and a literature review. In future work we plan to apply some of the above listed techniques to investigate how well they support improved stakeholder identification for decision making. We also plan to install RE roles in decision making processes and observe their effects on the process.

\section{ACKNOWLEDGMENT}

The authors would like to thank the researchers involved in the mentioned studies for their effort in collecting the data. The work is partially supported by a research grant for the ORION project (reference number 20140218) from The Knowledge Foundation in Sweden.

\section{REFERENCES}

[1] H. Saiedian and R. Dale, "Requirements engineering: making the connection between the software developer and customer," Information and Software Technology, vol. 42, no. 6, pp. $419-428,2000$.

[2] S. L. Lim, D. Quercia, and A. Finkelstein, "Stakenet: Using social networks to analyse the stakeholders of large-scale software projects," in 32Nd ACM/IEEE ICSE Conference, ser. ICSE '10, 2010, pp. 295-304.

[3] C. Pacheco and I. Garcia, "Stakeholder identification methods in software requirements: Empirical findings derived from a systematic review," in 2008 The Third International Conference on Software Engineering Advances, Oct 2008, pp. 472-477.

[4] C. P. E. Tovar, "Stakeholder identification in requirements engineering comparison of methods," in 10th IASTED International Software Engineering and Applications Conference, vol. 2, 2006, pp. 501-508.

[5] P. Bourque and R. E. Fairley, Eds., SWEBOK: Guide to the Software Engineering Body of Knowledge, version 3.0 ed. Los Alamitos, CA: IEEE Computer Society, 2014. [Online]. Available: http://www.swebok.org/

[6] C. P. Team, "Cmmi for development, version 1.2," Software Engineering Institute, Carnegie Mellon University, Pittsburgh, PA, Tech. Rep. CMU/SEI-2006-TR-008, 2006. [Online]. Available: http://resources.sei.cmu.edu/library/asset-view.cfm?AssetID=8091

[7] R. Singh, "International standard iso/iec 12207 software life cycle processes," Tech. Rep. 1, 2008.

[8] P. Kruchten, The Rational Unified Process: An Introduction, Second Edition, 2nd ed. Boston, MA, USA: Addison-Wesley, 2000.

[9] ISO/IEC/IEEE, "Iso/iec/ieee 42010 systems and software engineering architecture description," Tech. Rep., 2011.

[10] B. W. Boehm, Value-Based Software Engineering: Overview and Agenda. Berlin, Heidelberg: Springer Berlin Heidelberg, 2006, pp. 3-14.

[11] J. Savolainen and T. Mannisto, "Conflict-centric software architectural views: Exposing trade-offs in quality requirements," IEEE Software, vol. 27, no. 6, pp. 33-37, Nov 2010.
[12] R. S. Pressman, Software Engineering: A Practitioner's Approach, 5th ed. McGraw-Hill Higher Education, 2001.

[13] I. Sommerville, Software Engineering, 9th ed. USA: Addison-Wesley Publishing Company, 2010.

[14] S. Robertson and J. Robertson, Mastering the Requirements Process: Getting Requirements Right, 3rd ed. Addison-Wesley, 2012.

[15] Q. Gu, M. Parkin, and P. Lago, A Taxonomy of Service Engineering Stakeholder Types. Berlin, Heidelberg: Springer Berlin Heidelberg, 2011, pp. 206-219.

[16] S. Lauesen, Software Requirements: Styles and Techniques, 1st ed. Pearson Education, 2001.

[17] H. Sharp, A. Finkelstein, and G. Galal, "Stakeholder identification in the requirements engineering process," in Proceedings. Tenth International Workshop on Database and Expert Systems Applications. DEXA 99, 1999, pp. 387-391.

[18] E. Coakes and T. Elliman, "Focus issue on legacy information systems and business process engineering: The role of stakeholders in managing change," Commun. AIS, vol. 2, no. 1es, Jul. 1999.

[19] O. Preiss and A. Wegmann, "Stakeholder discovery and classification based on systems science principles," in Quality Software, 2001. Proceedings. Second Asia-Pacific Conference on. IEEE, 2001, pp. 194-198.

[20] R. K. Mitchell, B. R. Agle, and D. J. Wood, "Toward a theory of stakeholder identification and salience: Defining the principle of who and what really counts," The Academy of Management Review, vol. 22, no. 4, pp. 853-886, 1997.

[21] J. McManus, "A stakeholder perspective within software engineering projects," in 2004 IEEE International Engineering Management Conference (IEEE Cat. No.04CH37574), vol. 2, Oct 2004, pp. 880-884 Vol.2.

[22] E. Papatheocharous, K. Petersen, A. Cicchetti, S. Sentilles, S. M. A. Shah, and T. Gorschek, "Decision support for choosing architectural assets in the development of software-intensive systems: The grade taxonomy," in European Conf. on Software Architecture Workshops, ser. ECSAW '15. New York, NY, USA: ACM, 2015, pp. 48:1-48:7.

[23] K. Petersen, D. Badampudi, S. Muhammad Ali Shah, K. Wnuk, T. Gorschek, E. Papatheocharous, J. Axelsson, S. Sentilles, I. Crnkovic, and A. Cicchetti, "Choosing component origins for software intensive systems: In-house, cots, oss, outsourcing or services? a case survey," Transactions on Soft. Eng. - in print, vol. 2, pp. tba-tba, 2017.

[24] A. Aurum and C. Wohlin, "The fundamental nature of requirements engineering activities as a decision-making process," Information and Software Technology, vol. 45, no. 14, pp. 945 - 954, 2003.

[25] E. Papatheocharous, K. Wnuk, K. Petersen, A. Cicchetti, S. Sentilles, S. Ali Shah, D. Badampudi, and T. Gorschek, "The grade taxonomy: A taxonomy for decision support in the development of software-intensive systems," Empirical Software Engineering - under review, 2017.

[26] J. Bosch, "Speed, data, and ecosystems: The future of software engineering," IEEE Software, vol. 33, no. 1, pp. 82-88, Jan 2016.

[27] E. C. Groen, J. Doerr, and S. Adam, Towards Crowd-Based Requirements Engineering A Research Preview. Cham: Springer International Publishing, 2015, pp. 247-253.

[28] S. Sentilles, E. Papatheocharous, F. Ciccozzi, and K. Petersen, "A property model ontology," in 42th Euromicro Conference (SEAA). IEEE, 2016, pp. 165-172.

[29] U. Franke, "Towards preference elicitation for trade-offs between nonfunctional properties," in Enterprise Distributed Object Computing Conference (EDOC), 2016 IEEE 20th International. IEEE, 2016, pp. 1-10.

[30] N. KANO, N. SERAKU, F. TAKAHASHI, and S.-i. TSUJI, "Attractive quality and must-be quality," Journal of the Japanese Society for Quality Control, vol. 14, no. 2, pp. 147-156, apr 1984.

[31] A. M. Davis, "The art of requirements triage," Computer, vol. 36, no. 3, pp. 42-49, Mar. 2003.

[32] D. Dermeval, J. Vilela, I. I. Bittencourt, J. Castro, S. Isotani, P. Brito, and A. Silva, "Applications of ontologies in requirements engineering: a systematic review of the literature," Requirements Engineering, vol. 21, no. 4, pp. 405-437, 2016.

[33] Å. G. Dahlstedt and A. Persson, Requirements Interdependencies: State of the Art and Future Challenges. Springer Berlin Heidelberg, 2005, pp. $95-116$.

[34] M. A. Kaulio, "Customer, consumer and user involvement in product development: A framework and a review of selected methods," Total Quality Management, vol. 9, no. 1, pp. 141-149, 1998. 